\title{
Endovascular Covered Stent Treatment for Descending Aorta Pseudoaneurysm Following Coarctation of the Aorta Repair in an Infant
}

\author{
Farirai F. Takawira, FCPaed ${ }^{\text {a, }}$, Greenwood Sinyangwe, FCPaed ${ }^{a}$ and \\ Rene Mooloo, $\mathrm{MBCHB}^{\mathrm{b}}$ \\ a Department of Paediatric Cardiology, Steve Biko Academic Hospital and University of Pretoria, Pretoria, South Africa \\ ${ }^{\mathrm{b}}$ Department of Cardiothoracic Surgery, Steve Biko Academic Hospital and University of Pretoria, Pretoria, South Africa
}

\begin{abstract}
The development of a pseudoaneurysm is a rare complication following repair of a coarctation of the aorta. Surgical management of pseudoaneurysms is associated with high morbidity and mortality. We describe the successful endovascular deployment of a covered stent in a sick infant with a descending aorta pseudoaneurysm, following the repair of an aortic coarctation. We highlight the challenges we encountered. Endovascular repair is a safe palliative alternative to re-do open surgery in unstable infants with large pseudoaneurysms following aortic coarctation repair. The role of endovascular stents as the final definitive therapy will remain limited by the deployable, small-size stents in small, growing children.
\end{abstract}

(Heart, Lung and Circulation 2010;xxx:1-4) (C) 2010 Australasian Society of Cardiac and Thoracic Surgeons and the Cardiac Society of Australia and New Zealand. Published by Elsevier Inc. All rights reserved.

Keywords. Angiography; Aortic arch; Cardiac catheterization/intervention; Stents; Coarctation

\section{Introduction}

The development of a pseudoaneurysm is a rare but
well recognised late complication following repair of
a coarctation of the aorta. Surgical management of a pseu-
doaneurysm post-coarctation repair is usually associated
with high morbidity and mortality [1]. Currently, endovas-
cular treatment to isolate pseudoaneurysms of the aorta is
widely used in the adult population, with good outcomes
[1]. However, this approach has not been widely used in
children. We describe the successful endovascular deploy-
ment of a covered stent in an infant with a descending
aorta pseudoaneurysm, six months after the repair of an
aortic coarctation. We will highlight some of the challenges
in using this approach in small infants.

\section{Case Report}

The patient was a one-year-old child with Down's syndrome. He had surgical repair for a complete atrioventricular septal defect, cooarctation of the aorta and transverse arch hypoplasia at the age of six months, at which stage he was weighing only $3.5 \mathrm{~kg}$. A goretex graft was used to widen the hypoplastic arch and isthmus of the

Received 2 February 2010; accepted 28 June 2010

* Corresponding author at: Department of Paediatric Cardiology, Level D3 - Department of Paediatrics, Steve Biko Academic Hospital and University of Pretoria, P Bag X 169, Pretoria, 0001, South Africa. Tel.: +27 123545276; fax: +27 123545275 .

E-mail address: fari.takawira@up.ac.za (F.F. Takawira). aorta. He did well after the surgery until six months later when he presented acutely ill with a two-day history of respiratory distress.

On examination his weight was $5 \mathrm{~kg}$ and had failed to thrive. He appeared pale with a haemoglobin of $8 \mathrm{~g} / \mathrm{dl}$. His respiratory rate was $60 \mathrm{breaths} / \mathrm{min}$ and he had intercostal and subcostal recession. There was a mediastinal shift to the right. The left lung was dull to percussion with decreased air entry. His pulse was 150 beats/min with weak femoral pulses. The blood pressure was $80 / 40 \mathrm{mmHg}$ in the upper limbs and $50 / 30 \mathrm{mmHg}$ in the lower limbs. The heart sounds were audible over the right precordium. There were no murmurs or signs of congestive cardiac failure.

A chest radiograph demonstrated complete white out of the left chest and right mediastinal shift, with the trachea deviated to the right (Fig. 1). Echocardiography revealed patch repair of the AVSD with no significant residual intracardiac abnormalities and a large extra-cardiac fluidfilled mass in the left chest with evidence of swirling. A spiral computed tomographic (CT) scan (Fig. 2) demonstrated a large pseudoaneurysm of the descending aorta at the site of coarctation repair, just below the origin of the left subclavian artery.

After discussion with our surgical team, surgery was felt to be risky and have a high morbidity or mortality in this small infant. A percutaneous transcatheter therapeutic approach was therefore chosen over the more invasive traditional surgical approach. 


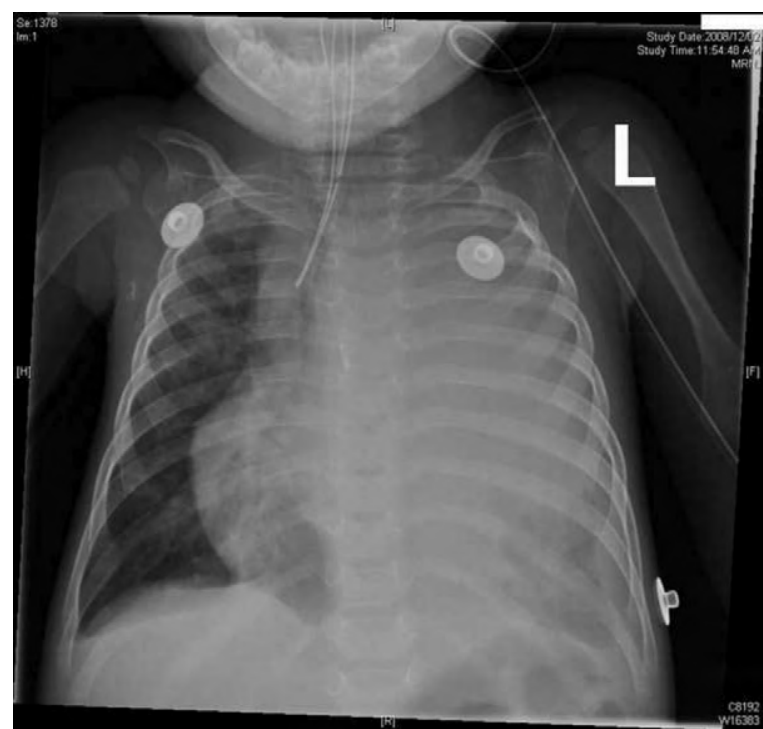

Figure 1. Chest radiograph demonstrating complete white of the left chest and the right mediastinal shift.

At cardiac catheterisation under general anaesthesia, both the right femoral vein and left femoral artery were cannulated. The large pseudoaneurysm was angiographically demonstrated (Figs. 3 and 4 ) to occupy most of the left hemithorax, compressing the left pulmonary artery and the left lung. After repeated aortic angiograms the opening into the pseudoaneurysm could be identified below the left subclavian artery. The transverse arch above the aneurysm was small and measured only $5 \mathrm{~mm}$. Therefore, a $5 \mathrm{~mm} \times 19 \mathrm{~mm}$ pre-mounted covered stent (Abbott Vascular, Abbott Park, Illinois, USA) was selected and deployed through a 7F sheath and a 7F guiding catheter in the descending aorta. With the stent straddling the opening into the aneurysm and using repeated angiography to check for ideal positioning, the balloon was inflated and the stent was successfully deployed (Fig. 5).

On repeat angiography (Fig. 6) the deployed covered stent was in good position and there was no more flow into the pseudoaneurysm. The opening of the pseudoaneurysm was occluded and the aneurysm was isolated. There was no obstruction to the left subclavian artery.

The left lung remained collapsed by the large now isolated aneurysm. Delayed surgical evacuation of the aneurysm was therefore undertaken 14 days later through a left lateral thoracotomy approach (Fig. 7). The left lung successfully re-expanded following the surgery and the infant was discharged from hospital two weeks later. Four months after the procedure he was still doing well. However, he has been noted to develop mild systemic hypertension, highlighting that he might outgrow the $5 \mathrm{~mm}$ stent soon.

\section{Discussion}

Early or late development of an aortic pseudoaneurysm is a recognised but rare complication following coarctation of the aorta repair [1]. It is more common after patch aug-
(A)

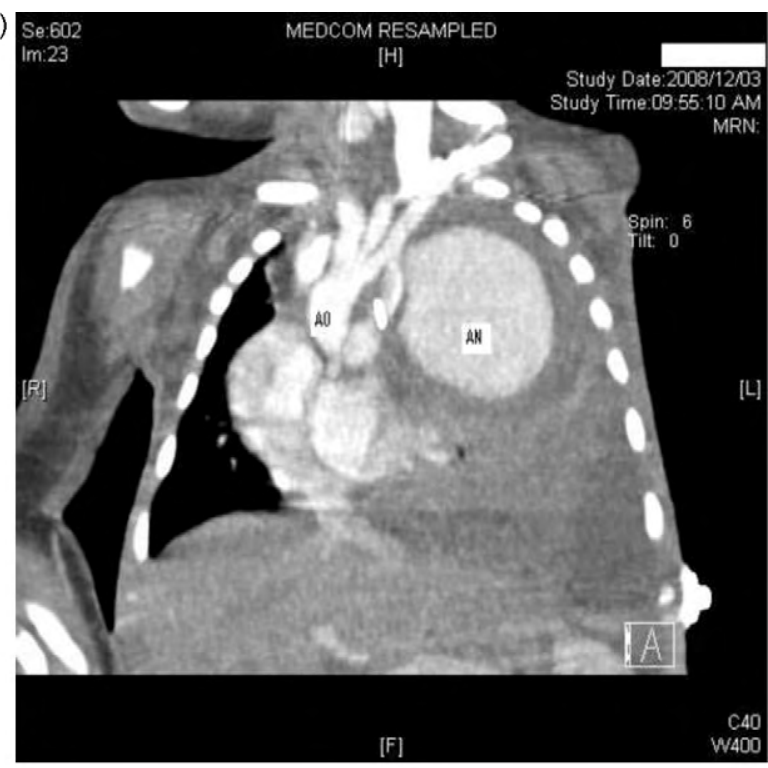

(B)

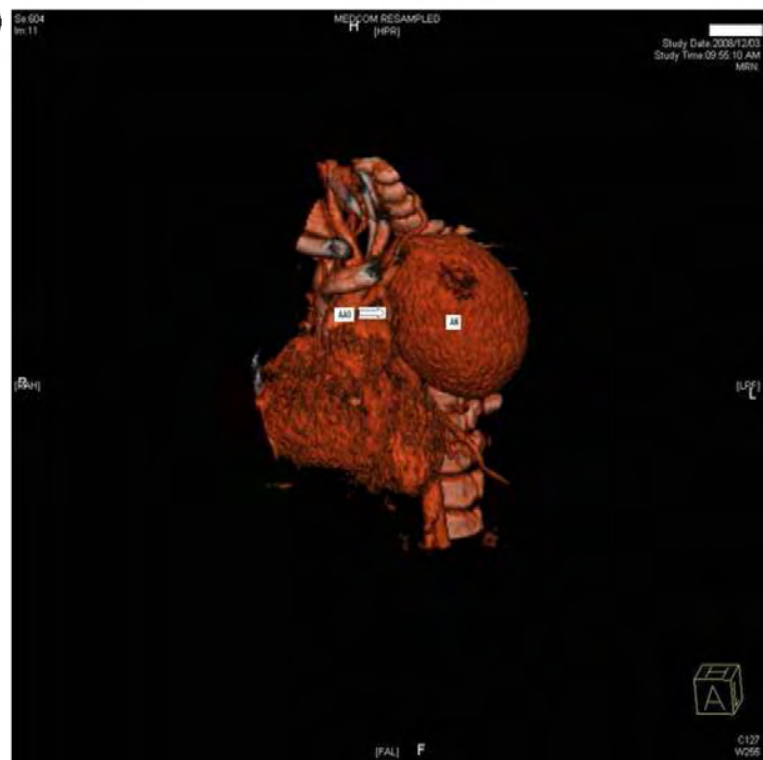

Figure 2. (A) Spiral computed tomographic (CT) scan demonstrating the large pseudoaneurysm of the descending aorta $(A O=$ ascending aorta; $A N=$ pseudoaneurysm) (B) Spiral computed tomographic (CT) scan ( $3 D$ reconstruction) demonstrating the large pseudoaneurysm of the descending aorta and the small isthmus and transverse arch (arrow) $(A A O=$ ascending aorta; $A N=p$ seudoaneurysm $)$.

mentation of the aorta than after end-to-end anastomosis $[1,2]$. It is often seen in patients with aortic arch hypoplasia $[3,4]$. It has also been described following balloon dilatation of native coarctation of the AO [5].

Surgical intervention has traditionally been used to manage these patients. Re-do surgery for aortic pseudoaneurysms is associated with high morbidity (paraplegia, recurrent laryngeal nerve paralysis, phrenic nerve injury) and mortality [6,7]. Conservative management is associated with a high rate of rupture and death [8]. Endovascular treatment with stents offers a less invasive treatment approach for this group of high-risk surgical 


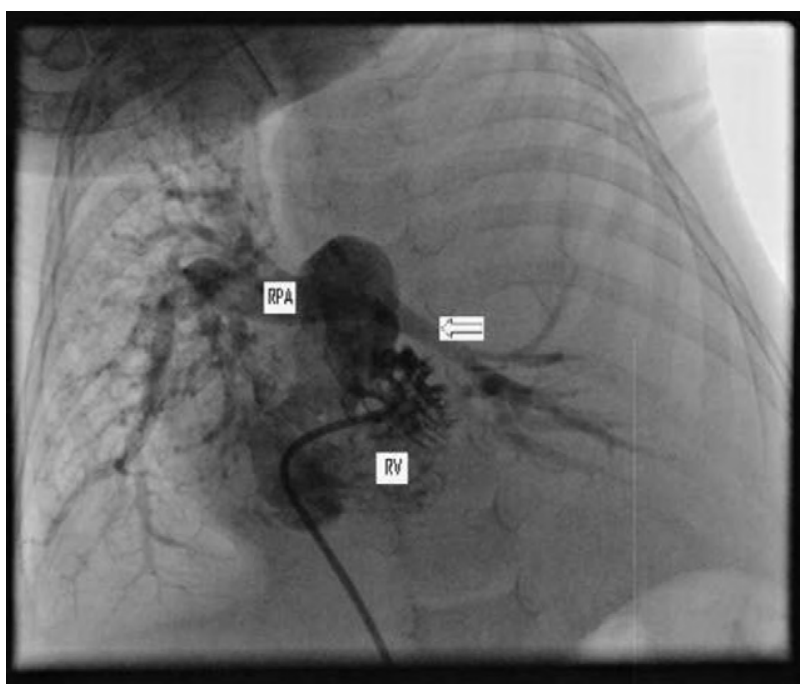

Figure 3. Right ventriculogram demonstrating the mass effect on the left hemithorax, compression of the left pulmonary artery (arrow) and the left lung and the right mediastinal shift $(R P A=$ right pulmonary artery; $R V=$ right ventricle).

patients. This procedure has been performed in adults and older children, but has not been described in infants $[1,6,8,9]$.

Our patient had early development of a pseudoaneurysm, occurring just six months after aortic coarctation repair. The endovascular stent approach was selected as the least risky in our patient and proved an early success. The challenges included the insertion of a large, $7 \mathrm{~F}$ femoral artery sheath required to deploy the stent in a small infant. There is also a limit to the size of stent that can be deployed, entailing the need for future intervention as the patient outgrows the small stent.

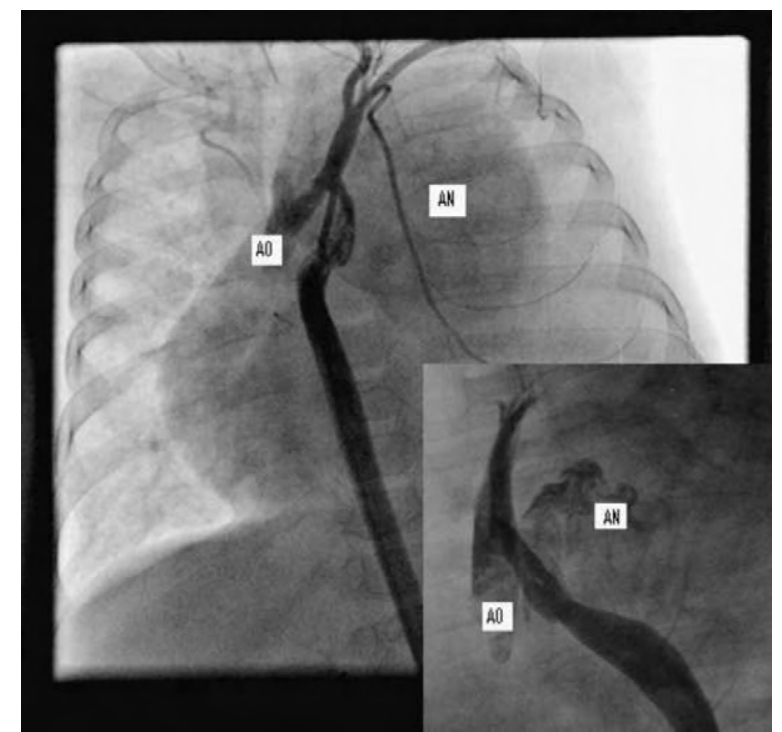

Figure 4. Descending aortagram in frontal and lateral (insert) views demonstrating the pseudoaneurysm $(A O=a$ arta; $A N=$ pseudoaneurysm $)$.

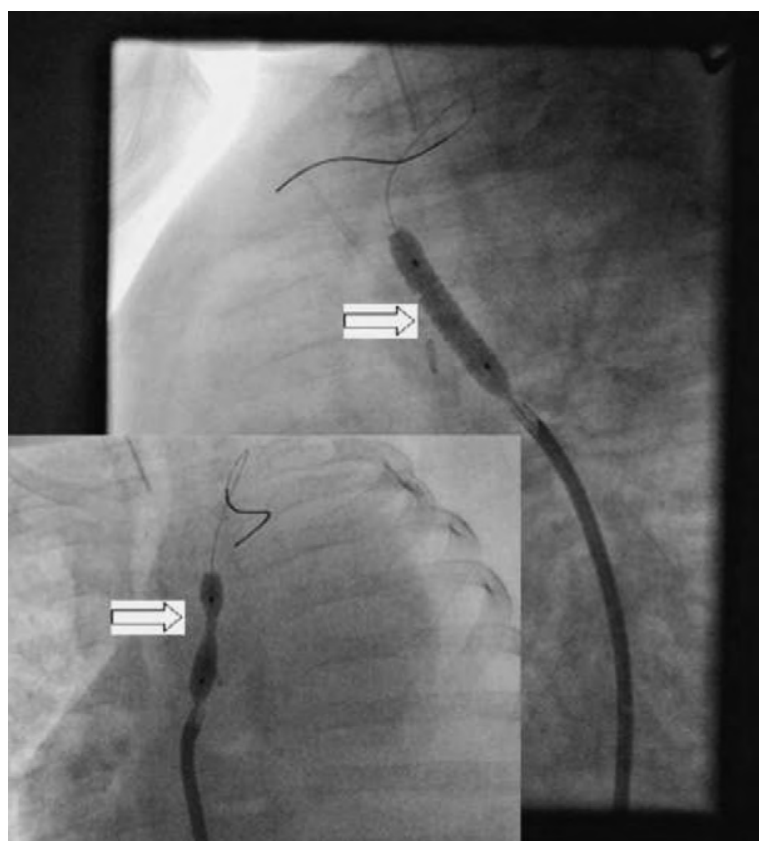

Figure 5. Fluoroscopy demonstrating slow inflation of the balloon to deploy the stent (arrows).

This case demonstrates that endovascular repair is a safe palliative alternative to re-do open surgery in unstable infants with large pseudoaneurysms following aortic coarctation repair. There are no reports up to now in the

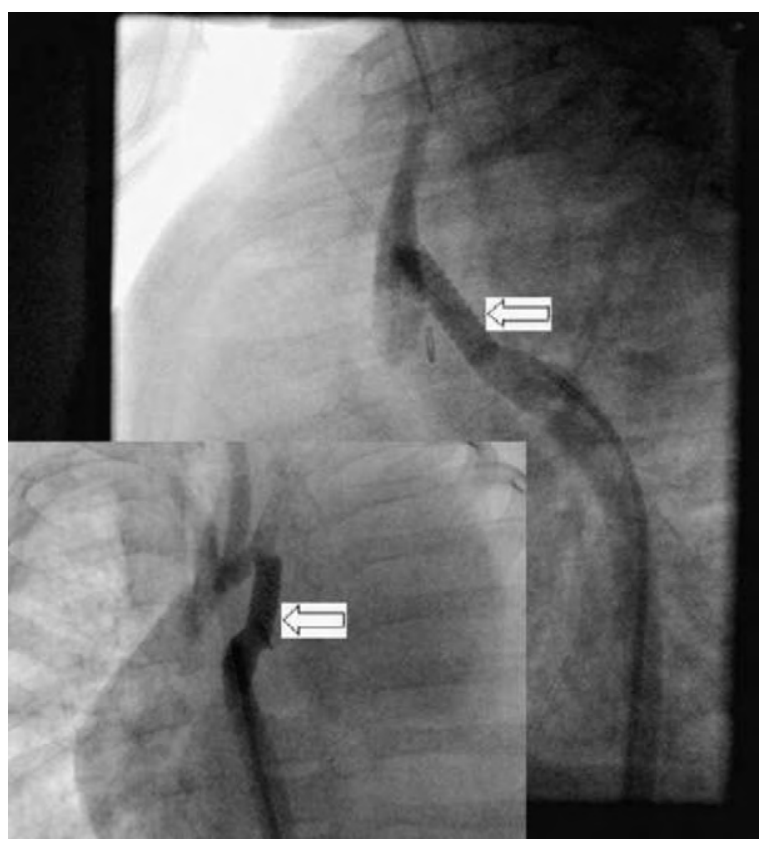

Figure 6. Descending aortagram in the lateral and frontal (insert) views demonstrating the stent fully deployed (arrows). There is no more leakage into the pseudoaneurysm. 


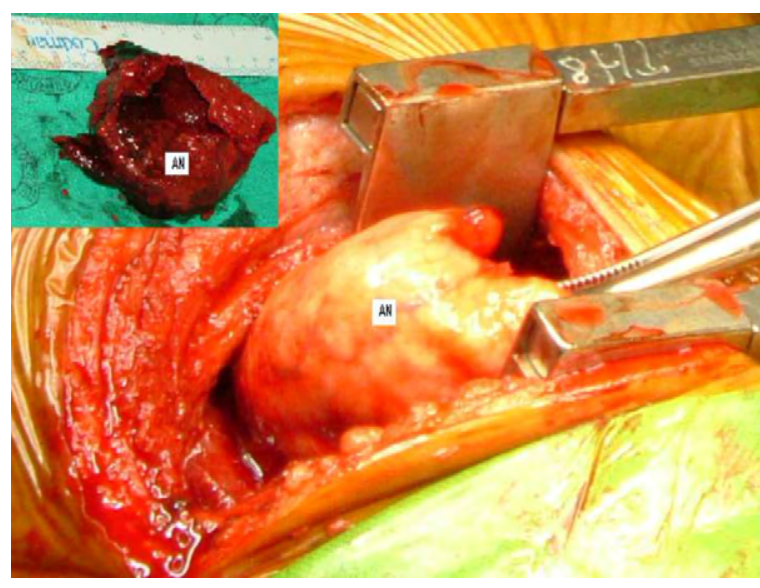

Figure 7. Pseudoaneurysm exposed intraoperatively and after removal (insert) $(A N=$ pseudoaneurysm $)$.

literature where this approach has been used in a young infant.

The role of endovascular stents as the final definitive therapy will remain limited by the deployable, small-size stents until such a time that re-expandable or selfexpandable stents have been developed for small, growing children.

\section{Acknowledgement}

We express our appreciation to Dr Belinda J. Mitchell for the intraoperative photography.

\section{References}

[1] Ince $H$, Petzsch $M$, Rehders $T$, Kische $S$, Korber $T$, Weber F, Nienaber CA. Percutaneous endovascular repair of aneurysm after previous coarctation surgery. Circulation 2003;108:2967-70.

[2] Von Kodolitsch Y, Aydin MA, Koschyk DH, Loose R, Schalwat I, Karck M, Cremer J, Haverich A, Berger J, Meinertz T, Nienaber CA. Predictors of aneurismal formation after surgical correction of aortic coarctation. J Am Coll Cardiol 2002;39:617-24.

[3] Bogaert J, Gewilling M, Rademakers F, Bosmans H, Verschakelen J, Daenen W, Baert AL. Transverse arch hypoplasia predisposes to aneurysm formation at the repair site after patch angioplasty for coarctation of the aorta. J Am Coll Cardiol 1995;26:521-7.

[4] Maxey TS, Serfontein SJ, Reece TB, Rheuban KS, Kron IL. Transverse arch hypoplasia may predispose patients to aneurysm formation after patch repair of aortic coarctation. Ann Thorac Surg 2003;76:1090-3.

[5] Huggon IC, Murdock IA, Cooke AC, Anderson DR. Acute pseudoaneurysm formation complicating balloon dilatation of native coarctation: treatment by delayed surgical repair. Pediatr Cardiol 1994;15:313-5.

[6] Bell RE, Taylor PR, Aukett M, Young CP, Anderson DR, Reidy JF. Endoluminal repair of aneurysms associated with coarctation. Ann Thor Surg 2003;75:530-3.

[7] Knyshov GV, Sitar LL, Glagola MD, Atamanyuk MY. Aortic aneurysms at the site of the repair of coarctation of the aorta: a review of 48 patients. Ann Thorac Surg 1996;61:935-9.

[8] Marcheix B, Lamarche Y, Perrault P, Cartier R, Bouchard D, Carrier M, Perrault LP, Demers P. Endovascular management of pseudo-aneurysms after previous surgical repair of congenital aortic coarctation. Eur J Cardio Thor Surg 2007;31:1004-7.

[9] Gawenda M, Aleksic M, Heckenkamp J, Kruger K, Brunkwall J. Endovascular repair of aneurysm after previous surgical coarctation repair. J Thorac Cardiovasc Surg 2005;130:1039-43. 